\title{
Kamu Üniversitelerinde Örgüt Kültürlerinin İncelenmesine Yönelik Bir Araştırma
}

\author{
Hürcan KABAKCI \\ hurcan@hacettepe.edu.tr
}

\section{A Research for Studying Organizational Cultures in State Universities}

\begin{abstract}
The aim of this research is to study organizational cultures in state universities. Thus, the organizational cultures of Hacettepe University, Faculty of Economics and Administrative Sciences (HU FEAS) and Ankara University, Faculty of Political Science (AU FPS) are studied and a comparative analysis is made. Both qualitative (focus group interviews) and quantitative (survey) methods are used in order to reveal the specific characteristics and strong/weak aspects of these two organizational cultures. The results show that, AU FPS has a stronger organizational culture. Besides, the factors effecting these organizational cultures to be strong/weak are also discussed in the extent of the research.
\end{abstract}

Keywords : Organizational Culture, Qualitative and Quantitative Approaches, Focus Group Interviews.

JEL Classification Codes : M14, L2, I20.

\section{Özet}

$\mathrm{Bu}$ çalışmanın amacı kamu üniversitelerinde örgüt kültürlerinin incelenmesidir. Bu bağlamda, Hacettepe Üniversitesi İktisadi ve İdari Bilimler Fakültesi (HÜ İ̈BF) ile Ankara Üniversitesi Siyasal Bilgiler Fakültesi (AÜ SBF) örgüt kültürleri incelenerek karşılaştırmalı bir analiz yapılmaktadır. Nitel (odak grup görüşmeleri) ve nicel (anket) teknikler bir arada kullanılarak iki farklı örgüt kültürünün belirgin özellikleri ile güçlü ve zayıf yönlerini açığa çıkarmak istenmektedir. Sonuçlar, AÜ SBF'nin daha güçlü bir örgüt kültürüne sahip olduğunu göstermektedir. Ayrıca bu iki kültürün güçlü ve zayıf olmasına etki eden nedenler çalışma kapsamında tartışılmaktadır. 
Hürcan KABAKCI 


\section{Giriş}

Örgüt kültürü, yönetim ve örgüt alanında son yıllarda üzerinde birçok çalışma yapılan konulardan biridir. Örgüt kültürüne gösterilen bu ilginin nedenleri arasında kavramın hem sosyo-ekonomik hem antropolojik hem de psikolojik boyutlarının olması, diğer bir deyişle çok yönlü ve karmaşık bir ilişkiler bütünü olması sayılabilir. Bunun yanı sıra örgüt kültürünün; örgütün amaç, strateji, yapı, süreç, ilişki, uygulama ve hatta performans gibi olguları üzerinde çok önemli bir etkisinin olduğu artık yadsınamayacak bir gerçektir (Brown, 1998; Schein, 2004). Özellikle 80'li yıllarda örgüt kültürünü tanımlamaya, özelliklerini veya unsurlarını ortaya çıkarmaya yönelik yapılan çalışmalar günümüzde yerini örgüt kültürünün örgüt, iş hayatı ve toplum üzerindeki etkilerini ve bunlarla ilişkilerini saptamaya öncelik veren araştırmalara bırakmıştır.

$\mathrm{Bu}$ çalışmanın amacı kamu üniversitelerinde örgüt kültürlerinin incelenmesidir. Bu bağlamda, Hacettepe Üniversitesi İktisadi ve İdari Bilimler Fakültesi (HÜ İ̈BF) ile Ankara Üniversitesi Siyasal Bilgiler Fakültesi (AÜ SBF) örgüt kültürleri incelenerek karşılaştırmalı bir analiz yapılmaktadır. İki farklı örgüt kültürünün özelliklerini, güçlü ve zayıf yanlarını açıklamak amaçlanmıştır. Üniversitelere yönelik yapılan örgüt kültürü araştırmaları incelendiğinde çoğunlukla akademik personelin alg1, tutum ve düşüncelerine ağırlık verildiği ve üniversite kavramına sıradan bir işyeriymiş gibi yaklaşıldığı görülmüștür. Oysa bir eğitim kurumu olan üniversiteler (veya fakülteler) eğitim sürecinin en önemli ayağını oluşturan öğrenci boyutuyla beraber irdelenmelidir. Bu düşünce tarzından yola çıkılarak, bu çalışmada hem öğrenciler hem de akademik personel bir arada incelenmektedir. (Öğrenci boyutunda İşletme Bölümü son sınıf öğrencileri esas alınmıştır). Araştırmada gözlem, görüşme ve anket gibi nitel ve nicel veri toplama teknikleri bir arada kullanılmıştır.

Kültürün görülebilen ve kolay fark edilebilen unsuru olan artefaklar (dil, hikâyeler, kahramanlar, gelenek ve törenler, kurallar gibi) üzerinden yapılan nitel ve nicel analizler genel olarak, AÜ SBF'nin güçlü bir örgüt külttürüne, HÜ Iİ̈BF'nin ise zayıf bir örgüt kültürüne sahip olduğunu ortaya koymaktadır. Ayrıca, çalışma kapsamında bu iki kültürün güçlü veya zayıf olmasına etki eden nedenler detaylı bir biçimde incelenmektedir ve HÜ İ̇BF'nin güçlü bir örgüt kültürüne sahip olabilmesi için üzerinde durulması gereken noktalar tartışılmaktadır.

Çalışma şu şekilde organize edilmiştir: İkinci bölümde örgüt kültürü kavramı tanımlanmakta, unsurları incelenmekte ve güçlü veya zayıf örgüt kültürlerinin özelliklerinden bahsedilmektedir. Üçüncü bölümde çalışmanın nitel ve nicel araştırma metotları hakkında bilgi verilmektedir. Dördüncü bölüm ise nitel ve nicel veri analizlerinin sonuçlarının tartışılmasına ayrılmıştır. Beşinci ve son bölümde çalışmanın sonuçları özetlenmektedir. Veri toplama sürecinde kullanılan anket ve görüşme soruları çalışmanın eklerinde yer almaktadır. 


\section{2. Örgüt Kültürü}

\section{1. Örgüt Kültürü ve Unsurları}

1950’li yıllardan bu yana araştırmacılar, örgüt kültürünün kuramsal yönünü ve içeriğini incelemektedirler. İlk olarak örgütsel sembollerde beliren örgüt kültürü, birincil aşamada üyelerine örgütü anlama ve daha sonraki aşamalarda da bu kültüre uyum sağlama, bu kültürü reddetme veya bu kültürü değiştirme yolunda genel bir çerçeve çizer (Frost ve Gillespie, 1998: 5).

Örgüt kültürü çalışanların örgütsel olaylar ve örgütsel süreçlere dair temel varsayımlarla ilgili yorumlarını biçimlendirir. O örgütün kendini ve çevresini nasıl anladığını ortaya çıkarıp kodlar ve böylece çalışanlar için örgütsel inanışlara ve amaçlara açıklık getirir (Sorensen, 2002: 73). Alvesson (1987)'a göre örgüt kültürü kavramı genel bir imgeyi, bütünleşmiş bir boyutlar/özellikler setini ve parçalardan öte bir bütünü ifade eder. Örgüt kültürü, belirli bir yer, zaman ve belirli bir grup için geçerli olan ve grup içindeki herkes tarafindan kabul edilen anlamlar topluluğudur (Pettigrew, 1979: 574). Brown (1998: 9)'a göre örgüt kültürü, örgüt içi uygulamalarda ve örgüt üyelerinin davranışlarında açığa çıkan, örgütün geçmişten bugüne zorluklarla başa çıkabilmek için geliştirdiği yöntemler, inançlar ve değerlerdir.

Schein (2004), günümüzde de geçerliğini koruyan ve pek çok yazar tarafindan da kabul görmüş olan örgüt kültürüne yönelik bir model geliştirmiştir. Bu modele göre, örgüt kültürü artefaklar, değerler ve varsayımlar olmak üzere 3 boyutta incelenmektedir.

Örgüt kültürünün en üst tarafinda sözsel, davranışsal ve fiziksel olmak üzere birtakım artefaklar vardır. Dil, şakalar, hikâyeler, mitler sözsel artefakları; tören ve seremoniler davranışsal artefakları; ofis düzeni, teknoloji ve mimari ise fiziksel artefakları oluşturur (Dyer Jr., 1988: 202). Artefaklar örgütün mimarisi, dili, teknolojisi, mit ve hikâyeleri gibi örgütsel değerleri açıklayan; âdet, tören ve seremonilerinde gözlemlenebilen görülebilir ürünleridir. Gözlemlenmesi ve algılanması kolay olmasına karşın tanımlanması ve çözümlenmesi oldukça zordur (Schein, 2004: 26). Bir kültürü çalışırken artefak ve davranışlar gibi belirgin durumların gözlemlenmesi varsayım, inanç ve değer gibi kolay fark edilemeyen bilişsel kavramları açıklamada kaynak olabilir (Sackmann, 1992). Örgütsel artefaklar örgütün ortak değer, norm ve diğer özelliklerini açıklayıcı bir niteliktedir ve örgütü diğer örgütlerden farklılaştıran kültürel yapısının ne olduğuna dair ipuçları içerir (Higgins ve McAllaster, 2004: 66).

Değerler örgütün amaç ve hedeflerini, düşüncelerini, standartlarına yansıtır ve örgütsel kimlik veya yönetim felsefesinde kendini gösterir (Dyer Jr., 1988:203). Örgütsel değer ve inançlar zor, belirsiz, kontrol edilemeyen veya bir krizin baş gösterdiği 
durumlarda örgütteki bireylere yol göstererek nelerin yapılması gerektiğini hatırlatır (Schein, 2004: 29). Örgütteki bireyin kişisel ve örgütsel davranışını yönlendiren bu temel değerler, örgütün hikâyeleri, törenleri ve kullandığı dilden ofis dekorasyonu, planı ve personel arasında geçerli olan kıyafet modeline kadar görünen birçok faktör üzerinde etkisini gösterir (Vural, 2003: 45).

Varsayımlar ise doğruluğunu sorgulamaksızın inanılan ve takip edilen düşünce, duygu ve algılardır. Uzun zaman benimsenen değer ve inançlar da örgütsel varsayımları oluşturabilir. Değişmesi veya değiştirilmesi oldukça zordur (Schein, 2004: 31). Temel varsayım, inanç, değer ve anlamlar bilinçaltında paylaşılır ve bunlara sahip olan insanlar için bile fark edilmesi çok zordur (Anthony, 1994: 30).

\subsection{Güçlü ve Zayıf Örgüt Kültürleri}

Güçlü bir örgüt kültürü zamanla oluşturulur ve geliştirilir. Uzun süredir örgütte bulunan çalışanların akıl ve belleklerinde gelişir ve buralardan desteklenir. Kendi kurumsal bilgi seviyesini anlayan ve üyelerine aktaran ve bunu örgütsel hafızasında değerli ve kalıcı bir varlığa dönüştürebilen örgütler başarılı bir kültür oluşturabilir. (Croft, 1990: 18; Knapp ve Yu, 1999: 21).

Zayıf kültürlerde değerler üzerinde uzlaşma sağlanamamıştır, alt kültürler arası ilişkiler yetersizdir. Güçlü bir örgüt kültürü, çoğunlukla, üyeler arasında artan işbirliği, dayanışma ve örgüte bağlllıkla sonuçlanır. Güçlü kültüre sahip örgütler çevreyi anlamaya yönelik yöntem ve yollara yüksek bir bağl1lık gösterirken, zayıf kültüre sahip örgütlerde örgütün çevresiyle olan ilişkisine yönelik farklı inançların heterojenliği mevcuttur (Bakan vd., 2004: 76-77; Sorensen, 2002: 88).

Kalıcı başarılar elde eden örgütlerde temel varsayımlar ve dolayısıyla örgüt kültürü sürekli pekişir. Başarılı oldukça örgütün iç çevresi dengeli ve istikrarlı olacağından, örgütün kültürü de güçlü kalmaya devam edecektir. Örgütsel değerlere ne kadar çok inanılır, önem verilir ve bu değerler ne kadar çok kişi tarafından paylaşılırsa, o örgütte güçlü bir örgüt kültürünün varlığından bahsedebiliriz. Değerlere inanan ve bağlllık gösteren çalışan sayısı arttıkça örgüt kültürü de güçlenecektir (Valentino, 2004: 402; Kemp ve Dwyer, 2001: 78).

Güçlü kültür, bir örgütün üyelerinin temel kültürel varsayım, inanç ve değerleri ne ölçüde paylaştıklarıyla ilgilidir. Eğer sosyal bir grubun üyeleri birtakım varsayım, inanç ve değerler üzerinde bir uzlaşma sağlayamamışsa bu grupta güçlü bir kültürün varlığından söz etmek mümkün değildir (Şişman, 2002: 146; O'Reilly vd., 1991). 
Güçlü kültürlerin karşılaşabileceği sorunlardan bazıları örgütsel uyuşukluk riski, örgütsel miyopluk ve geçmişten kopamama olarak karşımıza çıkmaktadır. Geçmişten beri aynı karar verme süreçlerini kullanma ve değişime ayak direyen kalıplaşmış ilişsiler de güçlü bir kültürün özellikleri arasında sayılmalıdır. Güçlü kültürler bazen değişime olan ihtiyacı algılamada zorluk çekebilir. Çünkü güçlü kültüre sahip örgütler ve bu örgütlerin üyeleri zayıf kültüre sahip bir örgüte ve bu örgütün üyelerine oranla hayatı belli bir şekilde algılama konusunda yüksek bir bağlılı̆ga sahiptirler. Bu bakımdan çevrede meydana gelen değişimleri belirlemede daha yavaş davranabilirler (Staber, 2003: 416-417; Sorensen, 2002: 76).

\section{Metodoloji}

Bu çalışmada, Hacettepe Üniversitesi İktisadi ve İdari Bilimler Fakültesi (HÜ İBF) ile Ankara Üniversitesi Siyasal Bilgiler Fakültesi (AÜ SBF) kurumsal kültürlerinin genel özellikleri itibariyle incelenmesi ve sınıflandırılması, güçlü bir kültür olup olmadıklarının ortaya konması ve elde edilen bulgular sonucunda karşılaştırılması amaçlanmıştır. Öğrencilerin yanı sıra akademik personel de yapılan derin görüşme ve odak grup görüşmeleri ile sürece dâhil edilmiştir. Bu bağlamda, her iki örgüt kültürü için de araştırmaya konu olan temel sorular şu şekilde özetlenebilir:

- HÜ IİBF ve AÜ SBF kurumları güçlü örgüt kültürüne sahip midir?

- Güçlü bir örgüt kültürü mevcut ise, bu kurumlarda güçlü bir örgüt kültürünün olmasını sağlayan temel etmenler nelerdir?

- Z Zayıf bir örgüt kültürü mevcut ise, bu kurumlarda zayıf bir örgüt kültürünün oluşmasina yol açan etmenler nelerdir?

Örgüt kültürü literatürüne bakıldığında hem nitel hem de nicel araştırma tekniklerinin bazen ayrı ayrı bazen de bir arada kullanıldığı söylenebilir. Örgüt kültürünün araştırıldığ bu çalışmada da, daha anlamlı sonuçlara ulaşmak amacıyla hem nitel hem de nicel araştırma teknikleri bir arada kullanılmıştır.

Nitel araştırma yöntemi bağlamında son sınıf öğrencileriyle odak grup görüşmeleri yapılmış ve Kemp ve Dwyer (2001) ve Brown (1998)'dan faydalanılarak oluşturulan 10 soru odak grup görüşmelerinde katılımcılara yöneltilmiştir (bkz. Ek 1). Benzer şekilde, her iki kurumda da bulunmuş ve bu sayede her iki kültürü yakından tanıyan akademik personel ile de derin görüşmeler yapılmıştır. 32 katılımcı ile odak grup görüşmeleri ve 3 katılımcı ile de derin görüşme olmak üzere her iki kurumdan toplamda 35 katılımcı aracılı̆̆ıyla veri toplanmıştır. Bunlara ek olarak her iki kurumda da belirli aralıklarla çeşitli gözlemler yapılmıştır. Derin görüşme ve odak grup görüşmeleri yöntemleriyle elde edilen veriler yorumlayıcı yaklaşımla çözümlenmeye ve örgüt 
kültürünün güçlü olup olmadığı örgütsel artefaklar üzerinden açıklanmaya çalışılmıştır. Yorumlayıcı yaklaşımda esas olan nesnelliğe ulaşmak veya genellemeler yapmak değil, öznel düşüncelerden yola çıkarak birtakım açıklamalar yapabilmektir.

Nicel araştırma yöntemi olarak da Brown (1998) tarafından geliştirilmiş ve örgüt kültürünün güçlü olup olmadığını ölçen 16 soruluk anket formu toplam 94 katılımcıya uygulanmıştır (bkz. Ek: 2). Hem nitel hem de nicel veri analizlerinin sonuçları ilerleyen bölümde tartışılmaktadır.

\section{Veri Analizi}

\subsection{Nitel Veri Analizi}

Nitel araştırma sürecinde bir örneği Ek: 1' de görülebilen 10 adet yarı yapılandırılmış soru kullanılmıştır.

Birinci soruda katılımcılara üyesi oldukları kurumu tanımlamada kullanırken akıllarına gelen ilk beş kelime sorulmuştur. HÜ İ̈BF öğrencileri çoğunlukla "tatminsizlik, belirsizlik, hedefsizlik, mezunlarla iletişimde kopukluk, imaj eksikliği” gibi kelimeler üzerinde yoğunlaşmışlardır. Olumsuz anlamdaki kelimelerin oldukça fazla olduğu göze çarpmakta, katılımcıların kurumsallaşma ve kurumla bütünleşme konularında zayıf bir inançları olduğu görülmektedir. İmaj eksikliği, belirsizlik ve hedefsizlik kelimeleri de zayıf bir kültürün sonuçları olarak ortaya çıkmaktadır. Benzer şekilde sosyal ve kurumsal ilişkilerde de belirgin bir tatminsizlik söz konusudur. Mezunlara veya örgütün geçmişine yönelik herhangi bir tanımlama yapılmamış olması da kurumun geçmişinden çok fazla beslenemediğine, örgütsel bilginin yeni üyelere aktarılamadığına, tarihsel bağın oldukça zayıf veya gelişmemiş olduğuna işaret etmektedir. AÜ SBF öğrencileri ise "gelenek, bürokrasi, zayıf sosyal ilişkiler, güçlü bir imaj, aidiyet ve mezunlar" gibi kelimeler üzerinde yoğunlaşmışlardır. Güçlü bir kültürden beklenildiği üzere gelenek, aidiyet ve güçlü bir imaj kelimeleri karşımıza çıkmaktadır. Sosyal ilişkilerin zayıflığından bahsedilirken aynı zayıflık biçimsel ve örgütsel ilişkilerde mevcut değildir. Bunun yanı sıra, mezunlar da kurum içerisinde çok önemli bir yer tutmaktadır; bu bakımdan, örgütsel hafızanın oldukça gelişmiş, örgütsel bilginin ise her düzeyde paylaşıldığı anlamı çıkarılabilir.

Íkinci soruda katılımcılara örgüt içinde kullanılan metaforların neler olduğu ve kurumsal bir dilin mevcut olup olmadığı sorulmuştur. HÜ İ̈BF öğrencileri örgütleri için "hapishane" metaforunu kullanmışlardır. Fakültenin kurulu olduğu kampüsün şehirden uzak olması, ders dışı aktivitelerin sınırlı olması, derslerin teorik tarafının yoğun, pratik kısmının ise yetersiz görülmesi gibi koşullar katılımcıların kurumlarını "hapishane" şeklinde tanımlamasını açıklayan başlıca etmenler olarak sayılabilir. Bununla beraber, 
örgütsel bir dil veya jargon mevcut değildir. AÜ SBF öğrencileri örgütlerine yönelik herhangi metaforik bir tanımlama getirmemekle beraber "inek" kavramına vurgu yapmışlar ve bunun kurum için çok önemli olduğunu söylemişlerdir. İnek çalışkanlığın, verimliliğin ve işe yaramanın bir sembolü olarak kullanılmaktadır. Katılımcılar, kurumlarının, tarihsel süreç içerisinde hem ülke hem de toplum için çok önemli olduğunu belirtmişlerdir. Buradan yola çıkarak, kurumlarının sadece bir eğitim kurumu olmadığını, çok önemli bir misyonu olduğunu ve kendilerinin de bu bilinçle yetiştirildiklerini açıklamışlardır. Örgüte ilişkin çeşitli şakalar, kısaltmalar, ifade ve tanımlamalar mevcuttur; bu bakımdan yüzeysel de olsa örgütsel bir dilden bahsedilebilir.

Üçüncü soruda ise örgütsel hikâye ve mitler araştırılmıştır. HÜ IIIBF öğrencileri örgüt içinde anlatılan, bilinen ve yaygın olarak kullanılan herhangi bir mit veya hikâye olmadığını belirtmişlerdir. AÜ SBF öğrencileri ise hem kendi dönemleri için hem de önceki dönemlere ait çok fazla hikâye ve mit olduğunu belirtmişlerdir. Bu hikâyelerin büyük bir çoğunluğunun eski mezunlar ve kurum içindeki akademik personel tarafindan öğrencilere aktarıldığını ve böylece iletişim ve paylaşım anlamında örgütsel bir bütünlük sağlandığını açılamışlardır.

Dördüncü soru kurumsal adet ve törenlere yöneliktir. HÜ İ̈BF öğrencileri çeşitli törenlerin var olduğunu ancak bunların biçimsel bir nitelik taşıdığı için kuruma has bir özelliğinin olmadığını vurgulamışlardır. Bu açıdan, yapılan mezuniyet veya tanışma törenlerinin bağlllık, kaynaşma, tatmin gibi duyguların gelişmesine katkısının sınırlı olduğu düşüncesi hâkimdir. AÜ SBF öğrencilerine göre kurum geleneğinin önemli bir parçasını tören ve seremoniler oluşturmaktadır. Zira belirli bir süreyi dolduran mezunlara özel seremoniler hazırlanması "mezun-akademisyen-öğrenci" arasındaki ilişki ve iletişimi oldukça güçlendirmektedir. Bunun yanı sıra AÜ SBF geleneğinde çok önemli bir yere sahip "inek bayramı" da aidiyet, birlik, beraberlik duygularını çoğaltmakta ve öğrencilerin kendilerini özel ve farklı hissetmelerini sağlamaktadır.

Beşinci soruda kurumsal kahramanların olup olmadığının cevabı aranmıştır. Ortaya çıkan sonuçlar örgütsel hikâyeler ile ilgili olan soruya verilen cevaplarla örtüşmektedir. HÜ İ̈BF öğrencileri örgütsel bir kahraman tanımlamakta oldukça zorlanmışlardır. Verdikleri cevaplar kendi dönemlerinde derslerini aldıkları birkaç akademisyenle sınırlıdır ve geçmişe yönelik bir bilgi içermemektedir. Diğer yandan, AÜ SBF öğrencileri kurumları için önem arz eden pek çok kahraman tanımlayabilmişlerdir. Özellikle mezuniyet sonrası devlet bürokrasisinde önemli görevler yapan, yüksek pozisyonlara gelen mezunlar, uzun yıllar kurum içerisinde yer almış belirli bir yaşın üstündeki akademisyenler ve toplum tarafından bilinen popülerleşmiş akademisyenler öğrencilerin gözünde örgütsel birer kahramandırlar.

Alttncı soruda, kurum içindeki biçimsel ve biçimsel olmayan ilişkiler araştırılmaktadır. HÜ İ̈BF öğrencileri hem biçimsel hem de biçimsel olmayan ilişkilerin 
çok sınırlı ve paylaşımdan uzak olduğunu belirtmişler; akademisyen-öğrenci ilişkilerinde zaman zaman belirli koşullara bağlı olarak kopmalar veya tıkanıklıklar olduğunu söylemişlerdir. Kurum içindeki sosyal paylaşım alanlarının son derece yetersiz olması, ders yüklerinin fazla olması, derslerin yoğun ve teorik ağılıklı olması katılımcılara göre ilişkilerin gelişmesine olumsuz yönde etki etmektedir. Benzer şekilde, AÜ SBF öğrencileri de biçimsel ve biçimsel olmayan ilişkilerin sınırlı olduğundan bahsetmişlerdir. Öğrencilere göre, derslerin teorik ağırlığının çok fazla olması, derslere devam zorunluluğunun olmaması, öğrencilerin sadece derslerde bir araya gelmeleri, ders dış1 ortak aktiviteler yapılmaması gibi koşullar ilişkilerin gelişimine engel teşkil etmektedir.

Yedinci soru güçlü bir örgüt kültürünün olup olmadığını sormaktadır. HÜ İ̈BF öğrencileri örgüt kültürünün oldukça zayıf olduğunu düşünmektedirler. Onları bu düşünceye iten temel sebepler aidiyet duygusunun yerleşmemesi, vizyon, misyon ve hedeflerdeki belirsizlik, mezun-akademisyen-öğrenci ilişkilerinin kurumsallaşmamış olması, örgüt içinde bilgi paylaşımı ve aktarımını sağlayan iletişim kanallarının eksikliğidir. AÜ SBF öğrencileri örgüt kültürlerinin oldukça güçlü olduğunu düşünmektedirler. Özellikle baskın "Mülkiyeli” kimliği ve Mülkiyeli olmanın ayrıcalıklı ve fark yaratan bir özellik olması, kurumun toplumda bilinirliği ve önemli bir imajının olması güçlü kültürün yarattığı önemli sonuçlardır. Aidiyet, kurumla bütünleşme ve sorumluluk hissi, sahiplenme gibi duygular da oldukça gelişmiştir.

Sekizinci soru olarak katılımcılara kuruma yönelik hangi değer ve inançlara sahip oldukları sorulmuştur. HÜ İ̈BF öğrencileri bireyselliğin ve rekabetin üst düzeyde olduğunu belirterek dayanışma, paylaşma, kararlara katılım ve iletişim süreçlerindeki eksikliğe dikkat çekmişlerdir. Mezunlarla ilişkilerin sağlıklı olmaması uzun vadeli ilişkiler kurmayı engellemektedir ve sahiplenme, aidiyet ve bütünleşme duygularını köreltmektedir. Benzer şekilde bürokrasinin çok olduğunu, teknolojik altyapının daha iyi olması gerektiğini, kariyer planlamasına yönelik programların olması gerektiğini vurgulamışlardır. AÜ SBF öğrencileri ise "Mülkiyelilik" kavramına çok önem verildiğini açıklamışlardır. Gelenek, dayanışma, aidiyet, bütünleşme, sorumluluk ve bilinç kavramlarının çok baskın olduğunu belirtmişlerdir.

Dokuzuncu soru örgüt kültürü ile fiziki çevre ve mimari arasındaki ilişkiyi ortaya çıkarmayı amaçlamaktadır. HÜ İ̈BF öğrencileri kurumun bulunduğu kampüsün şehre çok uzak ve ulaşımın büyük bir sorun olmasının bireylerin hem kendi aralarında hem de kurumlarıyla olan soysal ilişkilerin, etkileşim ve iletişimin azalmasına yol açtığını belirtmişlerdir. Kurum içindeki sosyal paylaşım alanlarının azlığı (kütüphanenin etkin çalışmaması, kantinin olmaması gibi) ise bireyleri fiziki çevre içerisinde daha az vakit geçirmeye yöneltmektedir. Mimari yapı ise örgüte ilişkin belirli bir kimliği yansıtmaktan uzaktır. AÜ SBF öğrencileri ise şehirle iç içe bir kampüste bulunmanın ulaşım, kurumsal kimlik ve bilinirlik açısından çok olumlu olduğunu söylemişlerdir. Kampüsün çok büyük olmaması, yurt sayısının sınırlı olması, kurumun fiziki çevresinin dar olması ise olumsuz 
özellikler olarak ön plana çıkmaktadır. Örgütün geçmişinden gelen tarihi binalar, sınıflar ve bahçeler ile koridorlarda sergilenen ve kurumun geçmişini anlatan çeşitli fotoğraflar kurumsal kimliği ve bağlllık duygusunu pekiştirip örgüt kültürünü güçlendirmektedir. Benzer şekilde fiziki çevre içerisinde sadece AÜ SBF öğrencileri tarafindan kullanılan bahçelerin olması, kurumun diğer fakültelerle etkileşimini azaltmasına rağmen içine dönük bir yapı oluşmasını ve kurumsal kimliğin pekişmesini sağlamaktadır.

Onuncu soruda ise kurumun tarihçesi ve geçmişine yönelik katılımcıların neler bildikleri araştırılmıştır. HÜ İ̈BF öğrencileri, örgütün geçmişinin uzun yıllara dayanmaması sebebiyle kurumsal geçmişin henüz oluşmadığı konusunda hemfikirlerdir. Ancak yaklaşık yirmi beş yıllık bir tarihi olan kurumlarının geçmişine yönelik bildikleri oldukça sinırlıdır. AÜ SBF öğrencileri ise örgüt geçmişinin kendileri için çok önemli olduğunu vurgulamışlardır. Zira yüz elli yıla yaklaşan geçmişiyle SBF sadece öğrencileri için değil toplum ve ülke için çok önemli ve özel bir yere sahiptir. Öğrenciler tarihten gelen bu misyonun sorumluluğu ve bilinci içerisinde hareket etme eğiliminde olup geçmişten bugüne süren geleneğin ve biriken bilgi ve deneyimin kendileri üzerinde çok büyük bir etkisinin olduğunu düşünmektedirler. Diğer bir deyişle kurumun özel ve uzun bir geçmişe sahip olması öğrencileri başarılı olma ve en iyisini yapma konusunda cesaretlendirmektedir.

\subsection{Nicel Veri Analizi}

Araştırma kapsamında anket yoluyla toplanan veriler SPSS programı yardımıyla analiz edilmiş, ortaya çıkan bulgular açıklanmaya ve yorumlanmaya çalışılmıştır. İstatistiksel analizin başlangıcında anket yoluyla toplanan verilerin güvenilirlik analizi yapılmıştır ve anketin güvenilirliğinin Cronbach Alfa ölçeğine göre $\% 95$ düzeyinde olduğu belirlenmiştir. Güvenilirlik analizinden sonra ise verilere ortalamalar analizi uygulanmış ve verilerin anlamlılık düzeyleri belirlenmeye çalışılmıştır. Ankette yer alan ve örgüt kültürünün güçlü olup olmadığını ölçen 16 soru için uygulanan ortalamalar analizi sonuçları Tablo: 1'de verilmektedir. 
Tablo: 1

Nicel Analiz Sonuçları

\begin{tabular}{|c|c|c|c|c|c|c|c|c|c|c|c|c|c|c|c|c|c|}
\hline & & 1 & 2 & 3 & 4 & 5 & 6 & 7 & 8 & 9 & 10 & 11 & 12 & 13 & 14 & 15 & 16 \\
\hline \multirow{5}{*}{$H \ddot{U} \ddot{I I} B F$} & Ortalama & 1,88 & 1,95 & 2,32 & 2,24 & 3,14 & 3,14 & 2,80 & 2,75 & 2,66 & 2,86 & 3,24 & 1,92 & 1,92 & 2,66 & 2,49 & 2,61 \\
\hline & \begin{tabular}{|l|} 
Sayı \\
\end{tabular} & 59 & 59 & 59 & 59 & 59 & 59 & 59 & 59 & 59 & 59 & 59 & 59 & 59 & 59 & 59 & 59 \\
\hline & Std. Sapma & 0,67 & 0,86 & 0,90 & 1,02 & 1,12 & 1,04 & 1,10 & 0,96 & 1,11 & 1,11 & 1,28 & 0,95 & 0,82 & 0,94 & 0,84 & 1,08 \\
\hline & En Az & 1 & 1 & 1 & 1 & 1 & 1 & 1 & 1 & 1 & 1 & 1 & 1 & 1 & 1 & 1 & 1 \\
\hline & En Cok & 4 & 5 & 4 & 5 & 5 & 5 & 5 & 5 & 5 & 4 & 5 & 4 & 4 & 4 & 4 & 5 \\
\hline
\end{tabular}

\begin{tabular}{|c|c|c|c|c|c|c|c|c|c|c|c|c|c|c|c|c|c|}
\hline \multirow{5}{*}{$A \ddot{U} S B F$} & Ortalama & 4,46 & 3,94 & 3,80 & 3,94 & 3,97 & 4,77 & 4,83 & 3,57 & 4,49 & 4,40 & 3,31 & 4,46 & 4,57 & 4,40 & 4,17 & 3,40 \\
\hline & Sayı & 35 & 35 & 35 & 35 & 35 & 35 & 35 & 35 & 35 & 35 & 35 & 35 & 35 & 35 & 35 & 35 \\
\hline & Std. Sapma & 0,98 & 1,08 & 1,16 & 1,19 & 0,98 & 0,65 & 0,75 & 0,98 & 1,04 & 1,03 & 1,08 & 0,98 & 0,81 & 0,95 & 0,92 & 1,06 \\
\hline & En Az & 1 & 1 & 1 & 1 & 2 & 2 & 1 & 1 & 1 & 1 & 1 & 1 & 1 & 1 & 1 & 1 \\
\hline & En Çok & 5 & 5 & 5 & 5 & 5 & 5 & 5 & 5 & 5 & 5 & 5 & 5 & 5 & 5 & 5 & 5 \\
\hline
\end{tabular}

Tablo: 2

\section{Anlamlılık Sonuçları}

\begin{tabular}{|l|c|c|c|c|c|c|c|c|c|c|c|c|c|c|c|c|}
\cline { 2 - 14 } \multicolumn{1}{c|}{} & $\mathbf{1}$ & $\mathbf{2}$ & $\mathbf{3}$ & $\mathbf{4}$ & $\mathbf{5}$ & $\mathbf{6}$ & $\mathbf{7}$ & $\mathbf{8}$ & $\mathbf{9}$ & $\mathbf{1 0}$ & $\mathbf{1 1}$ & $\mathbf{1 2}$ & $\mathbf{1 3}$ & $\mathbf{1 4}$ & $\mathbf{1 5}$ & $\mathbf{1 6}$ \\
\hline Kareler Toplamı & 145.751 & 87.320 & 47.987 & 63.904 & 15.347 & 58.786 & 90.703 & 14.976 & 73.143 & 51.802 &, 130 & 141.940 & 154.991 & 66.433 & 61.996 & 13.704 \\
\hline Serbestlik Derecesi & 1 & 1 & 1 & 1 & 1 & 1 & 1 & 1 & 1 & 1 & 1 & 1 & 1 & 1 & 1 & 1 \\
\hline Ortalama Kare & 145.751 & 87.320 & 47.987 & 63.904 & 15.347 & 58.786 & 90.703 & 14.976 & 73.143 & 51.802 &, 130 & 141.940 & 154.991 & 66.433 & 61.996 & 13.704 \\
\hline F değeri & 227.832 & 97.101 & 47.737 & 54.154 & 13.335 & 70.158 & 94.258 & 16.066 & 62.328 & 44.409 &, 089 & 153.157 & 233.192 & 74.881 & 81.810 & 11.846 \\
\hline Anlamlık & $\mathbf{, 0 0}$ & $\mathbf{, 0 0 0}$ & $\mathbf{, 0 0}$ & $\mathbf{, 0 0}$ & $\mathbf{0 0 0}$ & $\mathbf{0 0 0}$ & $\mathbf{, 0 0 0}$ & $\mathbf{, 0 0 0}$ & $\mathbf{, 0 0 0}$ & $\mathbf{, 0 0 0}$ & $\mathbf{, 7 6 6}$ & $\mathbf{, 0 0 0}$ & $\mathbf{, 0 0 0}$ & $\mathbf{, 0 0 0}$ & $\mathbf{, 0 0 0}$ & $\mathbf{, 0 0 1}$ \\
\hline
\end{tabular}

Örgüt kültürünün artefakları olan hikâyeler, şakalar, kahramanlar, tören ve seremoniler gibi örgütsel unsurlar (soru 1, 2, 3, 4, 6, 7) ile aidiyet duygusu (soru 9, 12, 14) açısından AÜ SBF ortalama değerleri HÜ İ̈BF ortalama değerlerinin tamamından oldukça yüksek çıkmıştır. Aynı şekilde, örgütün felsefesi, misyonu ve geleneği gibi unsurlar (soru $10,13,15)$ açısından da AÜ SBF ortalama değerleri HÜ İİB ortalama değerlerinden daha yüksektir. İş yapma tarzı, uzun süre çalışma gibi diğer unsurlar (soru 5, 8, 16) bakımından AÜ SBF ortalama değerleri ile HÜ İIBF ortalama değerleri birbirine yakın olsa dahi, bu unsurlarda da AÜ SBF değerlerinin yüksek olduğu görülmektedir. Uyum gösterme unsuru (soru 11) açısından ise elde edilen bulgular istatistiksel açıdan anlamlı değildir.

\section{Sonuç}

Çalışma kapsamında nitel (odak grup görüşmeleri ve derinlemesine görüşmeler) ve nicel (anket) veri analizi yöntemleri kullanılarak Ankara Üniversitesi Siyasal Bilgiler Fakültesi (AÜ SBF) ile Hacettepe Üniversitesi İktisadi ve İdari Bilimler Fakültesi (HÜ İIBF) kurumlarının örgüt kültürleri incelenmektedir. Sonuçlar genel olarak AÜ SBF'nin güçlü bir örgüt kültürüne, HÜ İİF'nin ise zayıf bir örgüt kültürüne sahip olduğunu ortaya koymaktadır. Anket sorularının anlamlı çıkan her değişkeni için AÜ SBF değerleri HÜ İIBF değerlerinin oldukça üstündedir. Ayrıca, yapılan görüşmelerde edinilen bilgi ve ortaya çıkan sonuçlar da istatistiksel olarak elde edilen sonuçları doğrulamaktadır. 
Güçlü bir kültürün en önemli unsurlarından biri olan kurumla bütünleşme ve aidiyet duygusu AÜ SBF kültüründe çok gelişmiştir. Mülkiyelilik kimliği bölümler üstü bir kimlik olup oldukça baskındır ve kurumu bir araya getiren ve bir arada tutan en önemli faktördür. AÜ SBF'nin köklü ve başarılarla dolu imrenilen bir geçmişe sahip olması da bu kurumu hem öğrenciler hem toplum nazarında özel bir yere koymaktadır. Bu bakımdan öğrenciler için kuruma ve kurumsal kimliğe hayranlık, kurum içerisine girmeden önce başlamakta; bu hayranlık kurum içindeki çeşitli tören, hikâye, şaka ve kahramanlar aracılığıyla iyice pekişerek güçlü bir sahiplik ve aidiyet duygusunu sağlamaktadır.

HÜ IIIBF için ise zayıf bir kültür söz konusudur ve aidiyet ve bütünleşme duyguları yok denecek kadar azdır. Örgütsel hafızanın gelişmemiş olması yani, geçmişte elde edinilen kurumsal bilgi, deneyim ve başarıların kurumsallaşamaması, söz konusu bilgi, başarı ve deneyimlerin örgütsel düzeyde paylaşılmasını engellemektedir. Örgütsel hafızanın zayıflı̆̆ özellikle mezuniyet sonrasında bireylerin kurumlarına yönelik olumsuz bir his beslemesine sebep olurken, başarı, deneyim ve bilginin bireysel düzeyde kalmasına, diğer bir deyişle paylaşılamamasına yol açmaktadır. Bunun yanı sıra makro bir faktör olarak "Hacettepeli" kimliğinin çeşitli sebepler yüzünden çok baskın olması alt kültürlerin ortaya çıkmasını dolaylı olarak önlemektedir. $\mathrm{Bu}$, sadece HÜ İ̈BF için değil, üniversitedeki diğer fakülteler için de geçerli olabilecek bir durumdur.

HÜ İİBF, güçlü bir örgüt kültürüne sahip olabilmek için öncelikle kurumsallaşmaya ve örgütsel hafızasını geliştirmeye ihtiyaç duymaktadır. Mezun-öğrenci ve akademisyen-kurum arasındaki hem biçimsel hem de biçimsel olmayan ilişkileri geliştirmeyi; iletişim, etkileşim ve paylaşım kanallarını çoğaltarak kurumsal kimliğini pekiştirmeyi amaç edinmelidir. Başarı, deneyim ve bilgi bireysel düzeyden örgütsel düzeye taşınmalı, öğrencilerin gerçekleştirdiği veya gerçekleştirmek istediği iş ve hedefler belirginleştirilerek onlara kurumsal açıdan değerli oldukları anımsatılmalı ve karşılıklı etkileşim sonucunda sahiplik, aidiyet ve bütünleşme hisleri geliştirilmelidir.

\section{Kaynakça}

Alvesson, M. (1987), “Organizations, Culture, and Ideology”, International Studies of Management and Organization, 17(3), 4-18.

Anthony, P. (1994), Managing Culture, Open University Press.

Bakan, İ. \& T. Büyükbeşe \& Ç. Bedestenci (2004), Örgüt Sirlarının Çözümünde Örgüt Kültürü̈, İstanbul: Aktüel Yayınları.

Brown, A. (1998), Organisational Culture, London: FT Pitman Publishing.

Croft, A.C. (1990), “The Case of the Missing Corporate Culture”, Public Relations Quarterly, 17 20. 
Dyer Jr, W.G. (1988). "The Cycle of Cultural Evolution in Organizations”, Eds. R.H. Kilmann \& M.J. Saxton \& R. Serpa, Gaining Control of the Corporate Culture, (200-229). San Francisco: Jossey-Bass.

Frost, S.H. \& T.W. Gillespie (1998), “Organizations, Culture and Teams: Links Toward Genuine Change”, New Directions for Institutional Research, 100, 5-15.

Higgins, J.M. \& C. McAllaster (2004), "If You Want Strategic Change, Don't Forget to Change Your Cultural Artifacts", Journal of Change Management, 4(1), 63-73.

Kemp, S. ve L. Dwyer (2001), "An Examination of Organisational Culture- the Regent Hotel, Sydney”, Hospitality Management, 20, 77-93.

Knapp, E. ve D. Yu (1999), “Understanding Organizational Culture”, Knowledge Management Review, 7, 16-21.

O’Reilly, C. \& J. Chatman \& D. Caldwell (1991), "People and Organizational Culture: A Profile Comparison Approach to Assessing Person Organization Fit"; Academy of Management Journal, 34(3), 487-516.

Pettigrew, A. (1979), “On Studying Organizational Cultures”, Administrative Science Quarterly, 24, $570-581$.

Sackmann, S.A. (1992), "Culture and Subcultures: An Analysis of Organizational Knowledge”, Administrative Science Quarterly, 37, 140-167.

Schein, E.H. (2004), Organizational Culture and Leadership, San Francisco: Jossey-Bass.

Sorensen, J.B. (2002), "The Strength of Corporate Culture and the Reliability of Firm Performance", Administrative Science Quarterly, 47, 70-91.

Staber, U. (2003), “Social Capital or Strong Culture?", Human Resource Development International, 6(3), 413-420.

Şişman, M. (2002), Örgütler ve Kültürler, İstanbul: PegemA Yayıncılık.

Valentino, C.L. (2004), “The Role of Middle Managers in the Transmission and Integration of Organizational Culture”, Journal of Healthcare Management, 49(6), 393-404.

Vural, B.A. (2003), Kurum Kültürü, İstanbul: İletişim Yayınları.

\section{EK: 1}

\section{Odak Grup Görüşme Soruları (Kemp ve Dwyer, 2001 ve Brown, 1998)}

1) Üyesi olduğunuz kurumu tanımlamak için kullanacağınız aklınıza gelen ilk beş kelime nelerdir?

2) Kurumunuzu tanımlamada kullanılan temel metaforlar nelerdir; kurum içerisinde kullanılan özel bir dil mevcut mudur?

3) Kuruma dair hikâye ve mitler var mıdır? Varsa, hangi kişi ve olaylarla ilgilidir? 
4) Kurumun belirli adet ve törenleri var mıdır? Varsa, içeriği nedir?

5) Kurumda kahramanlar mevcut mudur? Hangi kurumsal mesajları iletirler?

6) Kurum içindeki biçimsel ve biçimsel olmayan ilişkiler nasıldır? Bu ilişkilerde hangi değerler ön plana çıkmaktadır?

7) Örgüt kültürünün güçlü olduğunu mu düşünmektesiniz? Neden?

8) Kuruma yönelik hangi inanç ve değerlere sahipsiniz?

9) Fiziki çevrenin ve kurumun yer aldığg yerleşkenin belirli özellikleri nelerdir?

10) Kurumun tarihçesine yönelik neler söyleyebilirsiniz?

EK: 2

\section{Anket Soruları (Brown, 1998)}

\begin{tabular}{|c|c|c|c|c|}
\hline \multirow{2}{*}{\multicolumn{5}{|c|}{$\begin{array}{l}\text { Aşağıdaki ifadeleri göz önü̈ne alarak yandaki tablodan size en uvgun seçeneği işaretleyiniz. } \\
\text { 01. Burada herkes tarafindan bilinen okula has birçok hikâye vardır. }\end{array}$}} \\
\hline & & & & \\
\hline \multicolumn{5}{|l|}{ 02. Burada okula dair herkes tarafından bilinen birçok şaka vardır. } \\
\hline \multicolumn{5}{|l|}{ 03. Öğrencilerin paylaştığı okula has ortak bir dil mevcuttur. } \\
\hline \multicolumn{5}{|l|}{ 04. Okulu temsil eden kahramanlar bulunmaktadır. } \\
\hline \multicolumn{5}{|l|}{ 05. Okulun kendine has bir iş yapma tarzı vardır. } \\
\hline \multicolumn{5}{|l|}{ 06. Özel günlerde çeşitli tören ve seremoniler yapılmaktadır. } \\
\hline \multicolumn{5}{|l|}{ 07. Okulun çok eski ve farklı bir geçmişi vardır. } \\
\hline \multicolumn{5}{|l|}{ 08. Kişiler burada uzun süre çalışma eğilimindedir. } \\
\hline \multicolumn{5}{|l|}{ 09. Bu okul kendine özgü ve eşsizdir. } \\
\hline \multicolumn{5}{|l|}{ 10. Bu okulun kendine has bir misyonu vardır. } \\
\hline \multicolumn{5}{|l|}{ 11. Başarılı olabilmek bu okula uyum göstermeye bağlıdır. } \\
\hline \multicolumn{5}{|l|}{ 12. Öğrencilerde, kendini bu okulun bir parçası olarak görme hissi çok güçlüdür. } \\
\hline \multicolumn{5}{|l|}{ 13. Bu okulda, çok güçlü bir gelenek vardır. } \\
\hline \multicolumn{5}{|l|}{ 14. Öğrenciler, bu okul içerisinde olmaktan gurur duymaktadırlar. } \\
\hline \multirow{2}{*}{\multicolumn{4}{|c|}{$\begin{array}{l}\text { 15. Okulun kendine has bir felsefesi vardır. } \\
\text { 16. Okul, kendi kültürüne uygun insanları barındırma eğilimindedir. }\end{array}$}} & \\
\hline & & & & \\
\hline
\end{tabular}

